\title{
Growing vulnerability of the arid zones to drought and its impacts
}

\author{
I. Velasco \\ Hydrology Department, Mexican Institute of Water Technology, Mexico
}

\begin{abstract}
Although drought and aridity are two subtly different natural phenomena, they are not unrelated, and when they happen simultaneously, the implications can be disastrous.

Partly because of the natural climatic march, and partly as a consequence of the human activities, the deserts are increasing and droughts are becoming more persistent and recurrent. The variability and environmental changes are factors that trigger the combination desertification-drought as a vicious circle that leads to potential crisis conditions because of the severe impact on society and its activities.

Given the complexity of both phenomena, and their great coverage and slow but relentless development, it is very difficult to confront them with success, and then neither to avoid them, but we must make, as society members, our best efforts to formulate strategies and improve planning in order to confront its occurrence and to mitigate its impacts.

Nevertheless, the structural (engineering) aspect is decisive for this goal, the non-structural phase is probably of greater importance, and it is directly related with the social participation as a group, beyond the official institutions and government dependences; after all, we are all water users, and then we are all indebted to contribute and to participate in the actions that allow us to overcome these risk conditions in order to avoid expensive crises and catastrophes which injure the humankind.
\end{abstract}

Keywords: drought, desertification, environment deterioration, water stress. 


\section{Introduction}

Mexico is a country of weather and climate contrasts: although around $2 / 3$ of its territory is classified as arid or semi-arid [1,2], what is reflected in the inhabitant water availability (Figure 1); also, a significant part, mainly on coastal zones is subject to the impacts of the hurricanes.

Both extreme phenomena in connection with the water are potentially of high impact, and paradoxically, frequently they happen simultaneously: while Northern is razed by intense and extensive droughts, South and Southeast suffer the damages because the hurricanes.

The evidences point to that in the last years, these events (droughts and hurricanes) have become more persistent and more intense [6]. Wide regions exist in Mexico, where lack of rain has taken more than 10 continuous years, and also areas that have been whipped by several hurricanes in the same season.

Especially toward North of the Cancer Tropic, the rain it has been smaller than normal recurrently, what has caused severe problems of drought that have rebounded even in binational conflicts, for the inadequacy of water in the shared basins whose International Treaties have not been possible to complete [8], creating so much stress between water users and local authorities, and of diplomatic character too.

This way, the "normal" water demand has not been possible to satisfy fully, causing serious economic and social problems, propitiating that the available resources reach a use level higher than their capacity of natural regeneration, and then making that the risk of desertification grows significantly [9].

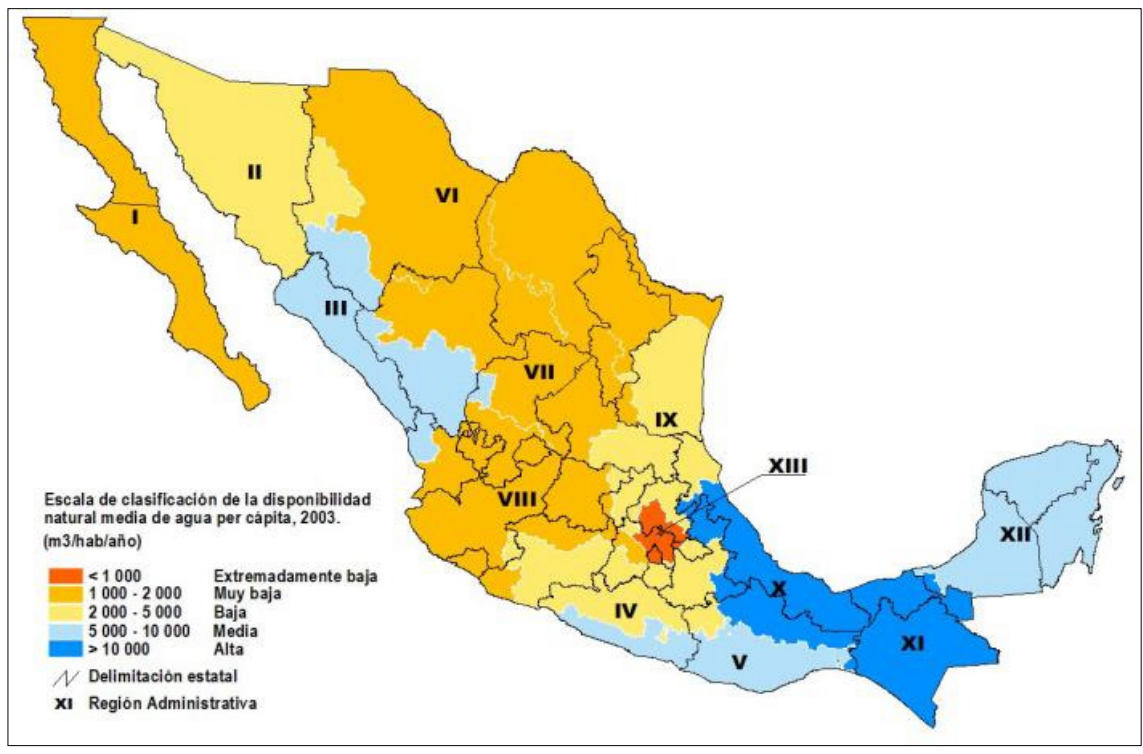

Figure 1: Classification scale of natural water availability, $\mathrm{m}^{3} /$ per capita/year, estimated for Mexico in year 2003 [2]. 


\section{Water availability}

According to UNO water standards [5], Mexico is a country with medium water availability (Figures 1 and 3), although this situation shows a trend to decrease, in function of the population increasing. It is considered that the rain annual average in Mexico is about $770 \mathrm{~mm}$ /year (Figure 2); nevertheless, its space distribution is very irregular, because while in some areas on the humid tropic it rains more than $3,000 \mathrm{~mm} /$ year, some areas in the North hardly reach $100 \mathrm{~mm}$ [7].

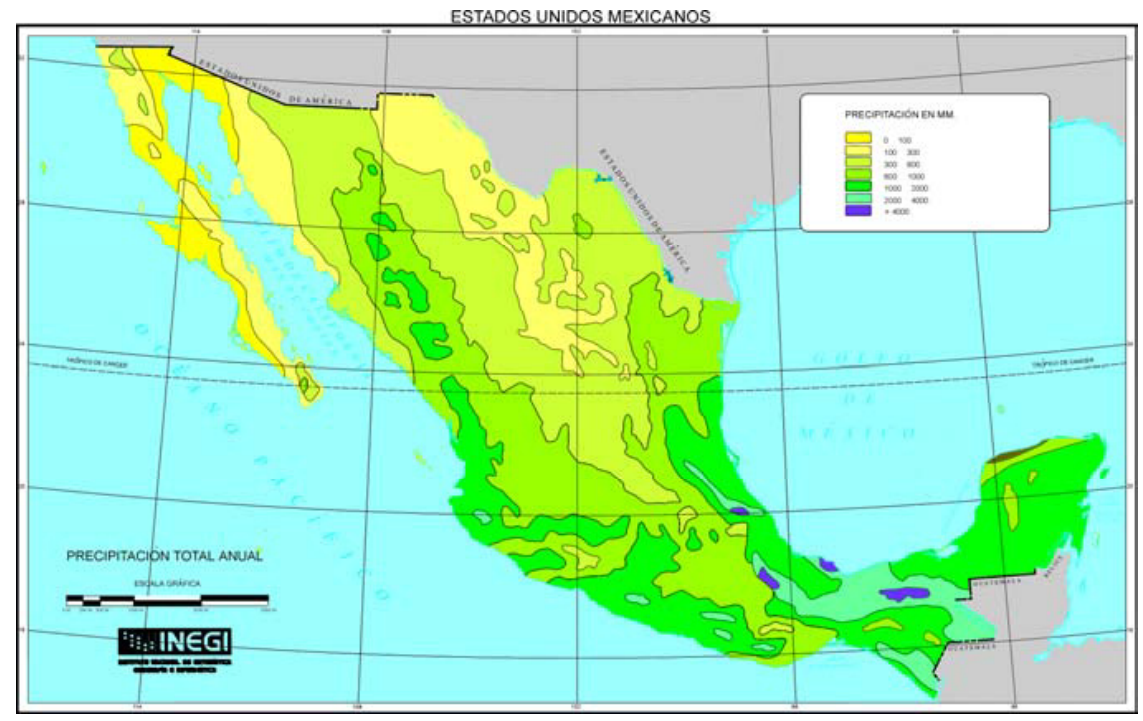

Figure 2: Annual average rainfall in México, in millimeters [1].

Paradoxically, most of the population, the industry and the agriculture are in the less rainy areas (Figure 3), creating with it strong pressures on the water and associate resources.

The population growing, the relative decreasing in the available water, in quality and quantity, and the every time bigger demand required to satisfy the necessities in the diverse uses, outlines serious problems to the environmental management, and increasing the stress in the use of the resource (Figure 4).

One aspect that has more influence in the environmental problems, related with the water requirements and availabilities, and with diverse products as vegetable fibers, wood, firewood, vegetable coal, etc., it is the ravage of the forests and natural grasslands, whose deterioration to quick rate, and with the minimal opportunity of recovery, it is causing that the desertification levels are really alarming $[1,5]$. In this way, soil, aquifers, surface streams, flora, and wildlife are reducing, and the disappareance risk is very high; that is unforgivable and a big tragedy, because the deep damage to environment and the natural balance. 


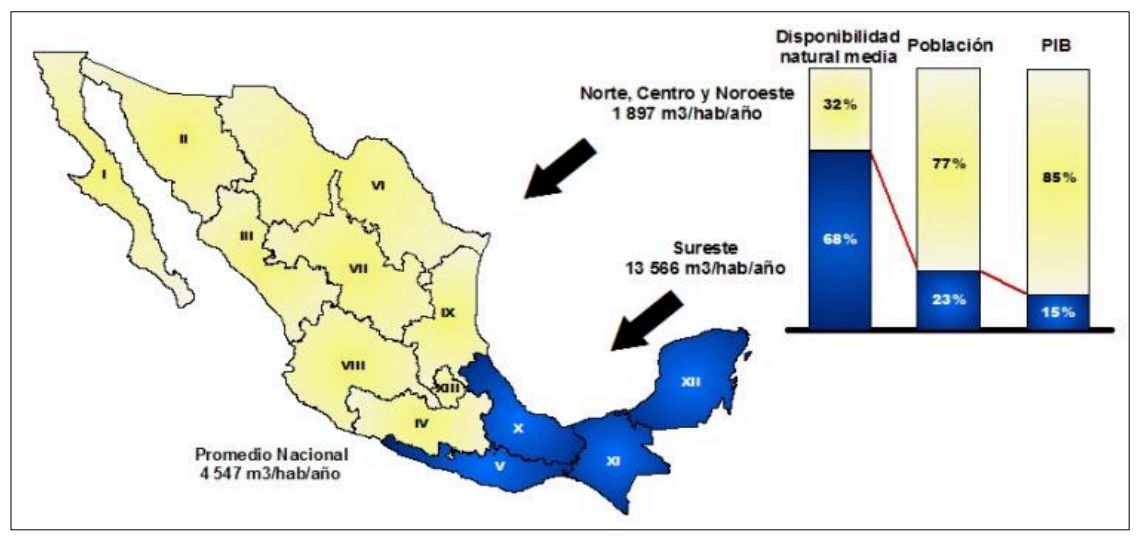

Figure 3: Natural water availability in Mexico, $\mathrm{m}^{3} /$ per capita/year [2].

\section{Environmental deterioration}

It is considered that among the years 1993 and 2000, 7,700 $\mathrm{km}^{2}$ of forest lands have been destroyed, 5,100 of which were forests or tropical jungle; the rate of deterioration in this sense it was about $1.1 \%$, one of the highest in the planet [2]. The main causes of this fact were the illegal pruning, the extensive cattle raising, agricultural land cleaning, and the forest fires.

In the last years, although the government efforts have diminished this rate, in general it is still high, and the reforestation has not still surrendered tangible fruits; in the best of the cases, the results are long-time, and on the other hand, to reforest is not only to plant small trees, but taking care of them so that they take root and be integrated to the environment, as well as so they reach the appropriate size.

Without the protection that the trees and the natural grasslands provide to the soil, this is degraded quickly, because the effect of water and wind, converting extensive areas before green and of great biological diversity, in unproductive barrens that finally give way, causing desolation and impoverishment, excluding wide geographical areas and population sectors (it Figures 5), condemning them to emigrate or to continue exploiting the resources until irreversible levels [7].

\section{Drought role}

This way, the drought is a trigger factor of the process, and according to its recurrence and severity, it becomes a lash of the affected areas, since its impacts are prolonged during years, and the social and economic costs are frequently beyond the reach of the affected people, and the government resources are insufficient, sometimes still to palliate the most elementary necessities [4]. Due to drought complexity, is very common to think that there will not be another drought episode equal or greater than the last, but unfortunately, subsequent events can be worse, if there is no planning to confront it. 


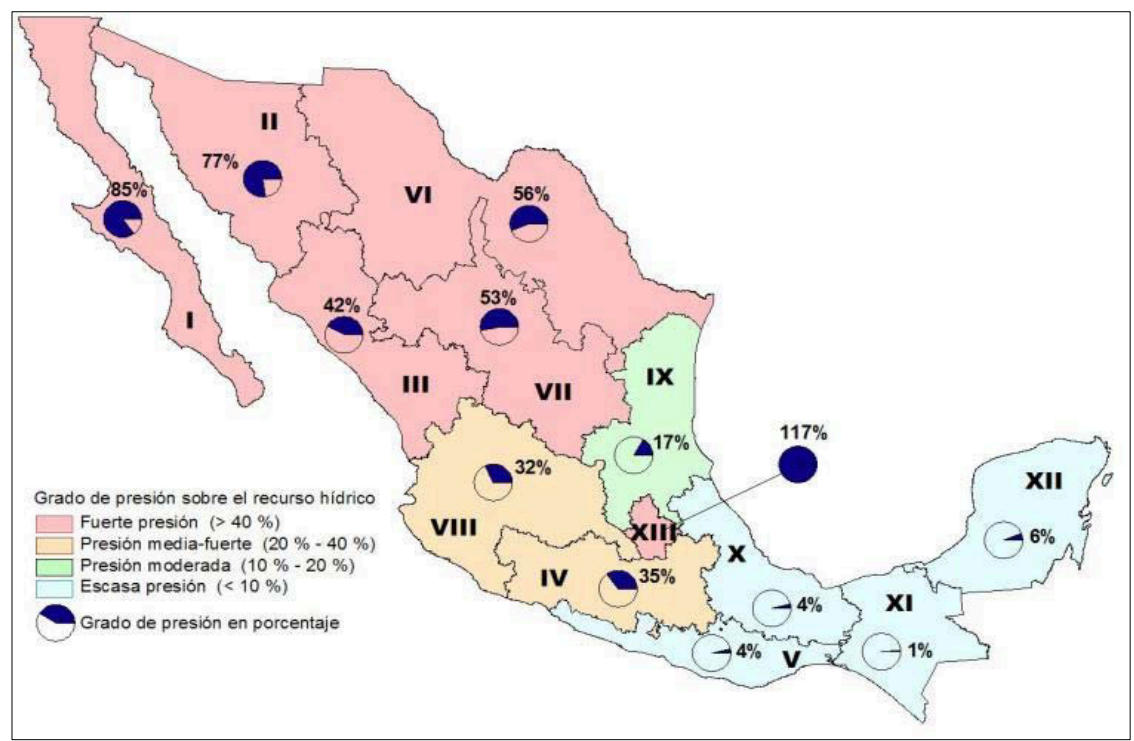

Figure 4: $\quad$ Stress level on available water in Mexico [2].

Although drought doesn't recognize political borders neither development levels, when it is presented, it affects more drastically the underdeveloped countries, in which it is capable to alter the natural and human environment significantly, in order to cause intense famines and human suffering.

These aspects make that, in a country like Mexico, the vulnerability to drought presence is a first-order factor. Irrigated areas, fundamental for the national agricultural development, and basically located in the areas that have been more affected by drought, they face serious problems of water availability, and the conflicts between uses and users they are something common and constant.

The areas that are non-irrigated, besides being more vulnerable, have a bigger risk of deterioration, since the population exploits to the limit the natural resources, and the recovering opportunities are also minimum [3]. In these areas is where the population inhabits are poorer than other population sectors, and where the underdevelopment conditions are accentuated; the problems like migration and marginalization reach levels of catastrophe.

\section{Conclusions}

The vicious circle of drought-deterioration-marginalization-povertydesertificación-abandonment is difficult to break, and just intense and constant joint efforts of the population and government are able revert the effects. 


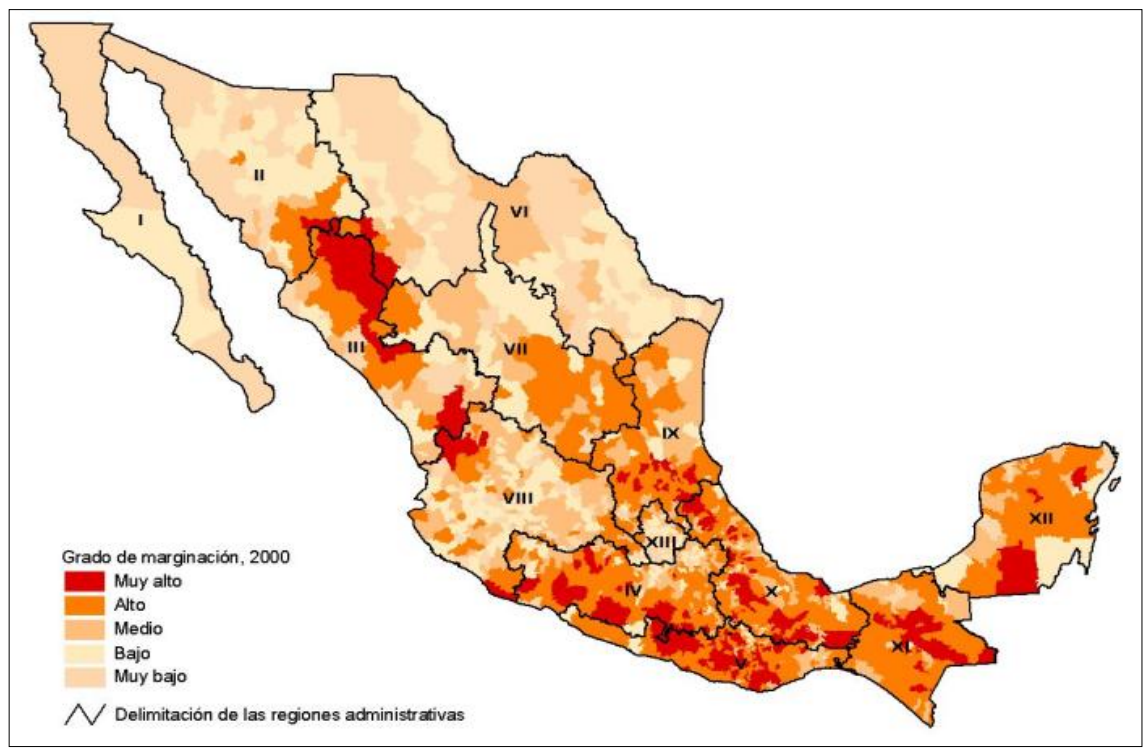

Figure 5: Population marginalization level in Mexico [2].

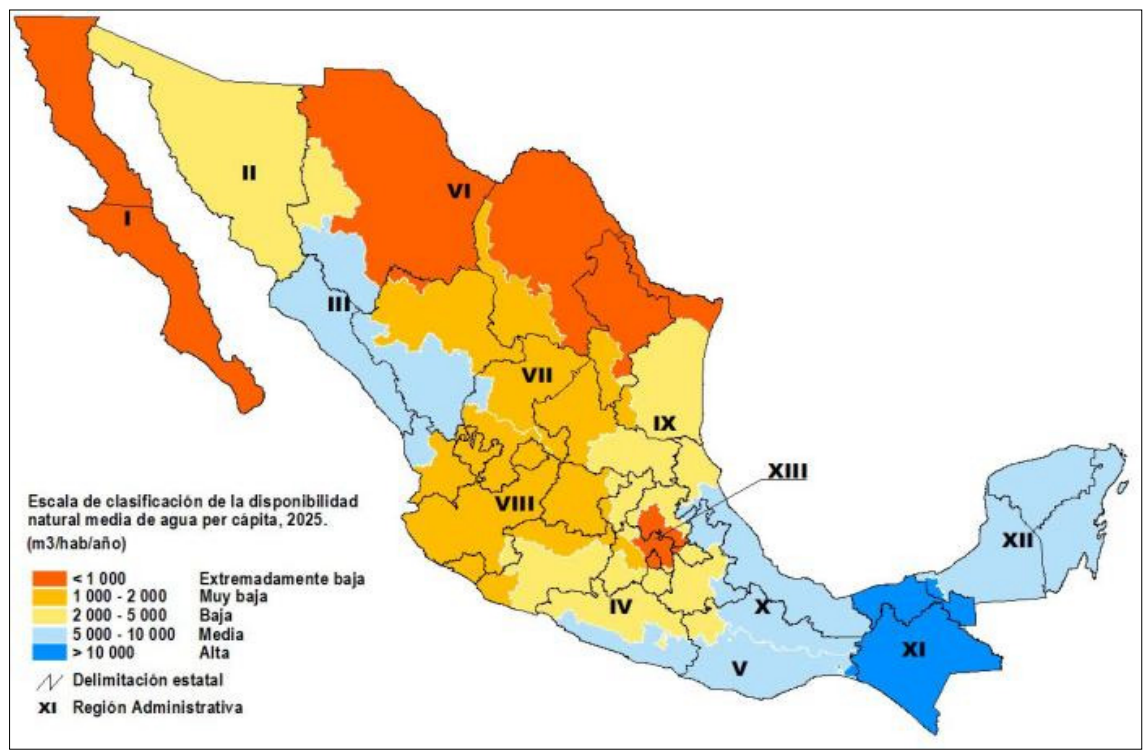

Figure 6: Classification scale of natural water availability, $\mathrm{m}^{3} /$ per capita/year, estimated for Mexico in year 2025 [2].

In connection with drought, the most appropriate form to mitigate the impacts and damages is the prevention, closely tied with the aspect of "water culture" or 
"water education". Only when there are appropriate preventive measures and in the fact that each part of the society and government assumes the list that correspond to each one, it will be possible that the environmental deterioration stops, to reach the human well-being and the sustainability in the use of water and associated resources is possible.

Natural conditions propitiates that Mexico is a low-medium water availability country; its $2 / 3$ territory is located in arid and semiarid zones, where water is naturally scarce (Northern desert fringe).

These regions plow highly vulnerable to natural phenomena like droughts and hurricanes. Mexico is making great efforts to improve water management through diverse mechanisms: laws, strategies, and investments in structural and non-structural aspects, in order to reach the conservation of its natural resources.

Future perspectives are positive if government and society fulfill their respective roles; otherwise, the panorama is not very pleasant (Figure 6).

\section{References}

[1] Análisis del cambio de uso del suelo. Mapas del Análisis del cambio de uso del suelo (Soil Use and Change Análisis). INEGI - UNAM, www.ine.gob.mx/dgoece/xid/dgioece/i usv/

[2] CNA (Comisión Nacional del Agua, Nacional Water Comisión). http://www.cna.gob.mx/eCNA/Espaniol/Estadisticas/Central/Estadisticas Agua_2004/SWM_2004.htm

[3] Desert Science. www.iydd.org/

[4] Martínez Fernández, Julia. Agua y sostenibilidad: algunas claves desde los sistemas áridos (Water and Sustainability: some Keys from the Arid Systems). Proc. of the Encuentro por una nueva cultura del agua en América Latina. Fortaleza, Brasil, pp. 15-23, 2005.

[5] OCDE. Evaluación del desempeño ambiental Mexico (OECD Environmental Performance Reviews: Mexico). SEMARNAT, México, pp. 67-91, 2003.

[6] Postel, S. Last Oasis. The Worldwatch Environment Alert Series. W. W. Norton \& Company. New York, USA. pp. 45-59, 1992.

[7] Velasco-Molina, H. A. Las zonas áridas y semiáridas. Sus características $y$ manejo (Characteristics and Management of Arid and Semiarid Zones). Editorial Limusa, S.A. de C. V. México. pp. 725, 1991.

[8] Velasco, I., F. J. Aparicio. Drought Detection and Evaluation Through a GIS for the Conchos River Basin, Mexico. Proc. of the Third International Symposium on Transboundary Waters Management. May, 29- Jun2. Session 2.3.C: Analytical Tools and Frameworks. Ciudad Real, Spain, 2006.

[9] Velasco, I., J. Aparicio, J. B. Valdés, J. Velázquez, T-W. Kim. Evaluación de índices de sequía en las cuencas de afluentes del río Bravo/Grande (Drought Indices Evaluation on the Rio Grande Tributary Watersheds). Ingeniería Hidráulica en México (Hydraulic Engineering in Mexico). Vol. XIX, No. 3, pp. 37-52. Mexico, 2004. 